\title{
ORTHODOX ECONOMICS AND ECONOMISTS: STRENGTHS AND WEAKNESSES
}

\author{
YEW-KWANG NG* \\ Monash University, Australia
}

\begin{abstract}
Economics is a very powerful discipline that focuses on some important aspects of our life, in particular, constrained maximization equilibrium in resource allocation. However, orthodox economics based on simplified models and many economists much captured by such models have too narrow a focus, ignoring many important factors including the importance of competition for relative standing, environmental disruption, and behaviour patterns inconsistent with the narrow concept of rationality. Economics has also become excessively formalistic, sacrificing relevance for technical sophistication. Extensions of economics to overcome these weaknesses have been and are being made. The incorporation of these advances will make economics more useful. But more time and resources may be needed to train economists properly.
\end{abstract}

Keywords: Economics; Economists; Scope; Relevance; Formalism.

The Nobel Memorial Prize in Economic Sciences for 2002 was awarded to Daniel Kahneman in behavioural economics and Vernon Smith in experimental economics. In both these two distinct but related areas, much emphasis is put on evidence, especially on individual decisions, that is contrary to the assumption of rationality adopted in economics. I welcome this award which should provide some support to those who are willing to extend orthodox economics and to explore areas beyond or even inconsistent with existing orthodox economics. This article discusses the strengths and weaknesses of orthodox economics and suggests aspects where it may be extended. Since most economists are

\footnotetext{
* Professor Ng Yew Kwang was the second distinguished economist appointed to the Goh Keng Swee Professorship chair in the Department of Economics, National University of Singapore, for a period of six months from July to December 2002. This paper is revised from the Goh Keng Swee public lecture "Some Limitations of Economics" delivered on 10 October 2002 at the National University of Singapore and from his talk in a panel discussion on "Economics: Present and Future" with Jack Knetsch and David Reisman at the Nanyang Technological University on 25 October 2002.

The Goh Keng Swee Professorship chair in Economics was established in 1996 to honour Dr Goh Keng Swee. Dr. Goh was born in Malacca in 1918 and educated at the Anglo Chinese School. He studied Economics at Raffles College, graduating with First Class Honours, and obtained his doctorate from the London School of Economics. In a long and distinguished career, Dr. Goh has been Singapore's major architect, economist and strategist. He used formidable intellect, academic knowledge, mastery of structure and process, and simple stubborn determination to help promote the development of modern Singapore.

This is an Open Access article published by World Scientific Publishing Company. It is distributed under the terms of the Creative Commons Attribution 4.0 (CC-BY) License. Further distribution of this work is permitted, provided the original work is properly cited.
} 
more familiar with the strengths than the weaknesses, I will focus more on the later. Personally, I regard economics as very important and useful. However, its usefulness could be significantly increased by the appropriate extensions.

As it happened, while I was visiting the Economics Department of the National University of Singapore in the second half of 2002, Jack Knetsch was also visiting there for two months (both visits may be largely credited to Euston Quah, the acting head until the middle of 2002). In fact, just on the night before the announcement of the Nobel prize, in a dinner hosted by Chen Kang, Head of the Division of Applied Economics, Nanyang Technological University, Jack was telling us that it was quite possible that the Nobel Committee might combine Kahneman with Smith. I had never heard a prediction as accurate as this! Did the fact that Knetsch has been a close joint author with Kahneman (a fact acknowledged by Kahneman after the announcement) have a role to play?

\section{Orthodox Economics and Its Strengths}

Orthodox economics is characterized by the rigorous (often mathematical) analysis focusing on resource allocation by analyzing rational maximization (under constraints) of consumers and producers (note the dichotomy) and the equilibrium of their interaction.

Several points/factors may be noted about the above description of orthodox economics. First, the emphasis is on resource allocation, in contrast to economic organization, institutions and similar related issues emphasized by those working somewhat on the fringes of core economic analysis (this is not to deny some rigorous analyses by fairly orthodox economists, including Nobel laureates. However, the core materials taught at both the undergraduate and graduate levels are much more focused on resource allocation as such. Similar provisos apply to the following points).

Secondly, the focus is on rational maximization behaviour rather than non-maximization and non-rational behaviour. Thirdly, the emphasis is on maximization behaviour under constraints, typically with the dichotomy between consumers who maximize utility under a budget constraint and producers who maximize profits under the constraints of given technology and market conditions. In addition, the government maximizes social welfare under the constraints of given resources and technology and subject to the maximization behaviour of individuals. Thirdly, conceptual equilibrium (either static or dynamic) and the associated comparative statics or dynamics are emphasized in contrast to the actual histories and non-equilibrium situations. Lastly, most economists also emphasize the efficiency of the market solution of the resource allocation problems under idealized conditions (including perfect competition, full knowledge, absence of external effects) and the inefficiency of government intervention.

Of course, many extensions to the core analysis outlined above have been achieved, including by previous Nobel laureates such as Gary Becker on rational behaviour outside the traditional areas of economics, Herbert Simon on bounded rationality, James Buchanan on self-interested behaviour of individuals who control governments and bureaucracies, and William Vickrey, James Mirrlees, George Akerlof, Michael Spencer, and Joseph Stiglitz on various aspects of incomplete and asymmetric information. 
The strengths of orthodox economics include:

- It captures very important aspects of economic activities.

- The analysis is very rigorous with very substantive and insightful results.

- The tools of constrained maximization and equilibrium can be expanded to cover nonorthodox factors; they will remain important in the future as well.

\section{The Limitations of Orthodox Economics}

I have neither the time nor expertise to deal with all the limitations of economics and economists and will focus on a few that are more related to my areas of interest.

\subsection{Narrow focus}

First, I think that many economists are two narrow, taking their simplified models as if it is almost perfect. In particular, most economists ignore ignorance and imperfect rationality. Many have a very narrow concept of rationality. I will give a real example to illustrate the point. A conference speaker made the point that a moderate level of inflation may be desirable as it helps to achieve changes in relative wages between different sectors to induce the required inter-sector changes. With a, say, 3\% inflation, maintaining the same nominal wages achieves a $3 \%$ reduction in real wages. Without inflation, we need a $3 \%$ reduction in nominal wages but people resist the same percentage reduction in their real wages much more strongly if it is done through cuts in nominal wages than if done through increases in the general price level. A commentator objected that this is not possible, as in either case, the set of feasible consumption (including leisure) is unchanged. It is irrational to prefer one to the other method (of reducing real wages). I must admit that I have such a preference but do not think that it is irrational, even though I may be imperfectly rational in other aspects. Not having one's wages increased by the rate of inflation may just be a delayed adjustment. Moreover, even if it is never to come by, it is a failure (of omission) to offset a more impersonal general increase in the price level. A reduction in nominal wages is certainly more offensive as it is a committed act. The fact that this difference is not present in the simple models of economists points to the incompleteness of such a simple analysis rather than to the irrationality of people.

On the other hand, the point above does not mean that no one has money illusion. In fact, even I probably have some money illusion. I am often slow to catch up with the general increase in prices (including my salary) and refuse to buy some goods which have increased in money prices. I concede that this is an instance of money illusion on my part and suspect that at least some others may have the same illusion, though whether the illusion is due to ignorance or irrationality may be difficult to determine.

For simplicity and to concentrate on the economic factors, economists typically use models where the utility function of an individual depends only on the amounts of goods and services consumed, and, where the income-leisure choice is analysed, the amount of leisure. Such simple models are very powerful in focusing on the purely economic factors and also very useful for teaching purposes. However, they must not be taken to be the 
whole truth as some economists apparently do. They have to be supplemented with many more complicated analyses.

As another example of how the almost exclusive confinement to their simple models has made many economists too narrow in their focus, consider Arrow's (1951, p. 528) example of the non-existence of general equilibrium (the example is more popularly available in Chipman 1965, as reprinted in Townsend 1971/1980). The economy consists only of two farmers and two goods, meat and vegetables. "Suppose Farmer Jones has some vegetables which he has grown and wishes to market. Assume that if the price of vegetables is high enough in relation to meat, he will sell some of them and buy meat with the proceeds, but below a certain price he will just consume his own vegetables; finally, if vegetables are free, he will want to consume an indefinitely large quantity of them. On the other hand, suppose Farmer Brown has a small and insufficient supply of meat, but a bumper crop of vegetables, more than he could possibly want for himself." Then, at any positive price of vegetables relative to meat, there is a negative excess demand for vegetables (as both farmers want to sell vegetables in exchange for meat). At a zero price of vegetables, excess demand for vegetables is infinite. Hence, at no price is the excess demand for vegetables equal to zero. There is no general equilibrium in this sense. However, this does not mean that "the price of vegetables will oscillate indefinitely" (Chipman as reprinted in Townsend 1980, p. 448). Rather, there will simply be no transaction. The economy will be at equilibrium with each farmer consuming his own endowment. Since this applies to all markets in the economy, this should be accepted as a "general equilibrium" in the wider sense. The narrower concept of equilibrium in terms of a set of prices that clears all markets is a Walrasian equilibrium. But not all general equilibria, even if confined to be competitive, need be Walrasian. Thus, we may have a million identical farmers Jones and a million identical farmers Brown, with each having no effect on prices. There still does not exist a price at which the excess demand for vegetables is zero. However, the economy will still be at equilibrium with no transaction, with each farmer consuming his own endowment. Thus, we have a non-Walrasian general competitive equilibrium. However, many general equilibrium theorists seem too much "captured" by their abstract theories to see this simple real-world possibility. Hence, in the absence of a Walrasian equilibrium set of prices, they think that must imply the price will oscillate. The no-transaction equilibrium does not enter the realm of possibility in their minds at all. ${ }^{1}$

\subsection{Do people behave as predicted by economic models?}

Behavioural and experimental economists (the areas of the 2002 Nobel Prize) have shown that people consistently behave in certain respects quite differently from that predicted by conventional economic analysis. I shall discuss some examples.

First is the division (or ultimatum bargaining) game of experimental economists (Guth, Schmittberger and Schwarze 1982, Roth 1995). Typically, an individual is given a sum of money (say \$100) to divide between herself and another individual who has the ultimate

\footnotetext{
${ }^{1}$ This paragraph also appears in $\mathrm{Ng}$ (2003c).
} 
power to decide to accept or reject. If accepted, both individuals get the respective amounts decided by the divider; if rejected, both get nothing. Simple economic models predict that the divider will award $\$ 99$ to herself, leaving $\$ 1$ to the other who will accept the $\$ 1$ instead of nothing. In fact, most individuals give around $\$ 25$ to $\$ 50$ and most offers of less than $\$ 20$ or so are rejected. In my view, such types of behaviour need not be irrational. Again, I regard myself as (almost) perfectly rational in this respect. However, I will certainly divide $\$ 50 / \$ 50$ as I think $\$ 20$ is a low enough price to pay for the sense of justice that I will enjoy by dividing $50 / 50$ (the other $\$ 30$ is to ensure that the other person will likely accept). The fact that such feelings of justice or fairness are not in the simple economic models only means that these models are simplified and not full reflections of the real world. Also, I will certainly reject all offers of less than \$20. Again, \$20 is a low enough price to pay to avoid the feeling of having to suffer the unfairness of being given a very one-sided division. Nevertheless, I must admit that, if $\$ 100$ million is to be divided, I will accept even the offer of just $1 \%$. Although the feeling of unfairness also increases with the amount of the sum involved, it does not increase proportionately. One million dollars is simply too large to pay for avoiding even this larger sense of unfairness. I may also honestly report that, if I am given the chance to divide $\$ 10$ million, I will probably offer $\$ 3.33$ million to the other person, keep the same amount for myself and use the rest to establish some scholarship. If I were to divide $\$ 100$ million, I will definitely divide 50/50 to ensure acceptance.

Next, consider the mug example used several times by Jack Knetsch. For the same mug, typically an individual will not pay more than \$4-5 for it if not yet in her possession. Once possessed, she will not be willing to sell it or give it up for as much as $\$ 12$ or so (for a discussion of such endowment effects, see Kahneman, Knetsch and Thaler 1991). I probably also have a similar preference which again I do not regard as irrational. I need more than a few dollars (in addition to the value of the mug to me) to induce me to engage in a transaction, especially if that could be seen as reflecting my desperation to obtain some cash. Why do I have to sell something I possess? Some extra compensation is of course needed. This is not irrational and does not imply that my marginal utility of money curve has a kink, as some behavioural economists infer. Simply because I do not want to incur the costs involved (inconvenience of transaction, being seen as in financial desperation, etc.). On the other hand, if I value an investment bond as being worth between $\$ 4000$ 5000 , an offer of $\$ 5,500$ will probably be sufficient to induce me to sell it, especially if I am fairly confident on my valuation.

Now consider the hotel-plus-voucher example. When given the choice between a weekend accommodation at a given hotel plus \$x cash (Option A) and an option (B) whose value is difficult to pin down, about half of the people picked one and the other half picked the other. When given another option (C) of exactly the same weekend accommodation at the same hotel plus the same \$x voucher (instead of cash) which can only be used to buy goods and services sold by the hotel, people could clearly see that this option is inferior to the hotel-plus-cash option. Accordingly, no one picked this additional option. But interestingly, a lot more people (about 70\%) picked the hotel-plus-cash option instead of the same option of uncertain value. Such a change of preference violates the strong independence axiom; the clearly inferior third option should not affect preference between the 
first two. The strong independence axiom is sensible (in fact compelling) within the certainty framework where the value of each option is definite. If I am definitely indifferent between $\mathrm{A}$ and $\mathrm{B}$ (or definitely prefer one to the other), this preference/indifference should not be affected by the presence or absence of an option $\mathrm{C}$ that is clearly inferior to $\mathrm{B}$. However, if my valuation of B is uncertain, my indifference between A and B (and the about equal likelihood of picking one out of the two) does not indicate my strict indiffer ence. Rather, it indicates only that I am not sure whether I prefer A to B or B to A. Though I definitely prefer A to $\mathrm{C}$, I cannot say that I also definitely prefer B to $\mathrm{C}$, as the value of $\mathrm{B}$ is uncertain. Since I am sure that I prefer A to C, the choice of A (out of the set A, B, and $\mathrm{C}$ ) gives me the certainty of picking the right one as far as rejecting $\mathrm{C}$ is concerned. The choice of B does not give such certainty. This gives A at least this kind of appeal, though I am still as uncertain as before about whether I prefer A to B or B to A. I may also be inclined to pick $\mathrm{A}$ (given $\mathrm{C}$ in the set of choice) for the above reason. A more sophisticated theory of choice under uncertainty should allow for such preferences.

On the other hand, many violations of axioms of rational choice (the expected utility hypothesis in particular) are due to mistakes of the decision makers. I could also be tricked to choose in a way in violation of expected utility maximization. Once discovered, I know that I should have chosen the other way. For such divergences, theories that are not based on expected utility may have some predictive power but do not have normative implications. Jack Knetsch and I discussed the issue of which types of divergences/violations should be accepted and which ignored for normative evaluation. We have the following agreement. On the one hand, there are some obvious cases of mistakes which should be ignored. For example, line segments of the same length may be perceived to be longer or shorter depending whether the extra lines at each end of the line segments are pointing inward or outward. Such visual perception mistakes should clearly be ignored (but see a remark at the end of this paragraph). On the other hand, such true preferences like the preference for not having one's nominal salary cut should be accepted, even if they are not allowed in the simple models of economics. But what are true preferences and where should the dividing line be drawn between the two types? We agreed that the ultimate criterion should be whether people's feelings (of being happy or unhappy) are affected. This is consistent with my view that happiness is our ultimate objective and is even

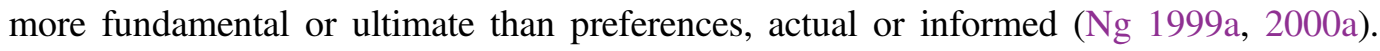
However, if we use happiness as the ultimate criterion, different contexts may affect whether certain mistakes or preferences may or may not affect happiness. For example, if I derive happiness from eating chocolate bars, I do not want to pay extra for those bars that only look longer. But if I use those bars to decorate my living room and I enjoy seeing longer looking bars, paying extra for bars that only look longer is appropriate.

\subsection{Many relevant factors ignored}

Most simple economic models ignore many important factors relevant for the issues analysed. For example, the production function approach to economic growth and development typically has capital, labour, and resources in the function but ignore the 
importance of institutions. Of course, the importance of institutions has been discussed by many economists. Nevertheless, Easterly (2001) could not find the word "corruption" throughout the 3047 pages of text in the four volumes of the Handbook of Development Economics published between 1988 and 1995 (Hillman 2002, p. 792) despite the fact that corruption is probably the single most important factor preventing development.

Virtually all economists emphasize the excess burden or distortionary costs (disincentive effects in particular) of taxation and the inefficiency of government spending, and hence have a pro-private sector or anti-public sector preference. While there are valid reasons for this preference, most economists are blind to the probably greater inefficiency of private spending (on which see the next paragraph), the corrective nature of taxation (due to the environmental disruption of most production and consumption and the external costs of conspicuous consumption, incomes and consumption should be taxed to begin with), and the likely negative excess burden of government spending (police protection give people higher incentives to earn the protected $\$ 80$ after tax than the unprotected $\$ 100$; see Kaplow 1996, Ng 2000b).

An important factor largely ignored by most economists is the competition for relative standing. True, relative-income effects were discussed as early as Rae (1834) and Veblen (1899) but the relevant policy implications have been almost completely ignored in the discussion of most relevant issues. With increasing affluence in most countries, absolute income and consumption levels have increasingly become unimportant. The problems are more those of over-eating, excessive cholesterols, over-cooling in the summer and excessive heating in the winter. Wherever I go, I got frozen by excessive air-conditioning in the tropics and in the summer and got cooked in the winter by excessive heating. When I went back to my hotel in Beijing, I had to take off all the six layers of clothing and still had to open the windows wide to avoid being cooked in the winter! Departmental stores, restaurants, hotels, etc. all try to outdo their competitors by providing excessive services. One example of this excessive competition is that the towels provided by most 3-5 stars hotels are so thick that they are difficult to use. So, excessive materials, washing, and energy are used to provide negative services at the margin and large and negative effects on the environment.

More economic growth for what? As I have already cited several times (Ng 2003a, 2003b), after about US\$5,000 per capita, higher incomes are significantly associated with neither the self-reported levels of happiness nor the quality-of-life indicators. People still desperately try to make more money (hence the term "rat-race") partly because of competition for relative standing (which is mutually destructive at the social level, with only the negative environmental disruption effects due to higher consumption and production) and partly because of the irrational materialistic bias due to both nature (our accumulation instinct) and nurture (peer pressure and commercial advertising) as well as the underestimation of the adaptation effect ("having seen the blue sea, it becomes difficult to appreciate waters"). We end up having quite possibly welfare-reducing growth (Ng \& $\mathrm{Ng}$ 2001), with the reduction offset probably by the contribution of the advancement of knowledge, making the levels of happiness showing some long-term constancy with 
oscillations. However, further research is needed to make the happiness data more accurate and interpersonally comparable (Ng 1996).

Using the traditional method of constrained maximization, but allowing for the importance of relative-income effects and the possible divergences between preference and welfare, I call for the extension of welfare economics from the level of preference to the ultimate level of welfare or happiness. The acceptance of this extension also makes the reformulation of many areas of economic applications necessary (wherever public policy is concerned, cost-benefit analysis in particular). Among others, the following conclusion is reached. In the presence of excessive materialism (denned by the positive excess of the marginal utility over marginal welfare of consumption), a cost-benefit analysis aiming at welfare maximization should adjust the marginal consumption benefits of public projects upward by a proportion determined by the proportionate excess of marginal utility over marginal welfare of consumption; the productive contributions of public projects should not be so adjusted ( $\mathrm{Ng} 2003 \mathrm{a})$.

Though there are many studies of imperfect competition in microeconomics, most macroeconomics is based on the explicit or implicit assumption of perfect competition. With this assumption and other simplifications, macroeconomists obtain the very unrealistic result of the neutrality of money. Changes in nominal aggregate demand in general and in money supply in particular do not affect the real economy. Accordingly, financial crisis, collapses in business confidence, etc. should have no real effects. Why are practical people so concerned about these then? I show that the relaxation of perfect competition alone may destroy the neutrality of money. Changes in nominal aggregate demand may either affect the price level only (the Monetarist case) or affect real output and employment without affecting the price level (the Keynesian case) and some other more remarkable cases (Ng 1977, 1980, 1982, 1986, 1992, 1999b). Despite this, economists (as surveyed in Dixon and Rankin 1994) who do allow for imperfect competition in their macro models since around the mid-1980's still ignore the possibility of the non-neutrality of money (see Ng 1998).

Economists' belief in the efficiency of the market is supported by the success of market economies in the real world as well as the theoretical result on the Pareto optimality of competitive equilibria. Both points are very important and I strongly support the transition to market economies in Eastern Europe and China. However, many economists tend to absolutise the point and do not make adequate allowance for some factors ignored. For example, increasing returns are prevalent in real world economies. This is inconsistent with perfect competition which rarely prevails. ${ }^{2}$ A more important factor limiting the perfect efficiency nature of the market economy is the prevalence of external effects, in particular, environmental disruption. It is remarkable that, with the world facing serious environmental disruption, there are still economists in the ivory tower refusing to accept the existence of external effects and believing that, with the proper definition of property rights, the market will take care of everything. True, property rights are extremely

\footnotetext{
${ }^{2}$ However, generalized increasing returns at the economy level due to the economies of specialization facilitated by the division of labour may be consistent with perfect competition. See Buchanan and Yoon (1999); see also Yang and Ng (1993) for an analysis of such generalized increasing returns that dispenses with the dichotomy between consumers and producers.
} 
important. But no matter how we define property rights, we are going to have some important external effects left unresolved by the market due to high transaction costs, ignorance, etc. Economists may also be right to say that, even when the market fails to achieve perfect efficiency, government intervention typically makes matters worse. We must not make the mistake of the Roman emperor who awarded the trophy to the second singer after only hearing the singing of the first. We may even need to have some healthy scepticism against government intervention due to its poor track record. However, at least for the major market failure of environmental disruption, we desperately need some public actions, even if we can only have some fairly inefficient ones. Trying to save the patient using non-ideal methods is better than to let the patient die!

\subsection{Excessive formalism}

A visible change in academic economics is its increasing mathematical formalism. I am not against the use of mathematics and have used a fair amount of it myself and from as early as my first paper in economics ( $\mathrm{Ng} \mathrm{1965).} \mathrm{The} \mathrm{use} \mathrm{of} \mathrm{mathematics} \mathrm{allows} \mathrm{us} \mathrm{to} \mathrm{put} \mathrm{ideas} \mathrm{in}$ a more precise manner. Mathematical analysis may also lead to results not observable intuitively. However, for results that could be obtained and seen to be true without using mathematics or using only simpler mathematics, simplicity should be preferred. However, current professional practice suggests that the reverse is true. A commentator of a paper of mine said that there was no need to assume a Euclidean space as the analysis could be conducted in a more general vector space. However, if the point could be shown and seen in the simpler and more intuitive Euclidean space (where we all live in and know well), why use a more abstract and less simple though mathematically more general vector space? (The point is that the higher generality in the mathematical space does not make the economic models more general; it just makes the correspondence between the mathematics and the models represented more difficult to see). For the representation of real economic variables like quantities of goods and services, the Euclidean space is all economists require. The use of more complicated mathematical space is excessive formalism.

When I spent my first study leave visiting the U.K. in 1973, I asked an economist (not a mathematician) what he was working on. He answered, "HP [or SP] space." "What is HP space?" I asked. "You do not know what HP space is?" As if all economists should know what HP space is (is HP for "high-powered" or SP for "sexy and pedantic"? I am not sure). "The only space I use is Euclidean space", I said. "Euclidean space is OK", he said, in a tone as if suggesting, "but not sophisticated enough". I did not and have not checked up on what HP or SP space is, as I am absolutely sure that no economist needs to use HP space, except for showing off their mathematical sophistication. Even if he needed to use HP space, he should not have answered my question that way. Any space is only a mathematical technique that we use to help analyze a given economic problem. The problem should be the area we are working on, not the mathematical techniques. We are economists, not mathematicians.

The tendency towards excessive formalism is fostered by the inclination of academic journals to publish sophisticated papers. Editors and referees may or may not consciously aim for technical sophistication as such. Roughly speaking, publishability may be taken to 
be a function both of the importance of content and presentation (including technical sophistication). Since scholars (who act simultaneously as researchers trying to publish their own papers and as editors/referees judging the papers of others) tend to see their own papers as more important, they require the papers of others to be technically more sophisticated before publication is regarded as acceptable, even in the absence of other more partial types of bias. This in turn makes scholars put more emphasis on techniques, leading to a vicious cycle towards excessive formalism (see Ellison 2002 for an analysis). Given this tendency, editors and referees should make a conscious effort to shift emphasis towards relevance in contrast to technical sophistication. While rigour is important, relevance is even more important. One can do very rigorous analysis on how the square root of the last five digits of one's bank account number correlates with certain other variables, but such analysis is useless. On the other hand, many important issues may involve variables difficult to measure and compare. But it is more important to give roughly correct answers to important questions than to give exact answers to irrelevant questions. In this respect, the willingness of some leading journals in economics to publish papers on happiness (e.g., Frank 1997, Oswald 1997, Ng 1997, Frey and Stutzer 2002) is encouraging. Many economists suspect the reliability of happiness measures and may even look down upon people who work on imprecise variables. However, they should look at their own backyard. Even the measurement of GNP is subject to all sorts of inaccuracies. We used the imperfect measure for decades. Then came the PPP (purchasing power parity) adjustment which overnight increased the Chinese (and Indian) GNPs by 4 (6 or more) times from this single adjustment alone! Most happiness measures may not be very accurate but I doubt that such huge adjustments will ever be necessary for the average figure of any nation.

The bias towards excessive formalism is likely to be made worse by the recent emphasis on research performance, especially as represented by publications in leading refereed journals, by universities in many countries both in the West and in East Asia (however, the current level of excessive formalism is so high that one may reasonably hope that it will generate countervailing forces to check or even reverse its growth). This emphasis itself has a lot of sense in trying to improve academic standards and accountability of academics. However, due to the existing tendency towards excessive formalism, the emphasis may worsen the situation, leading to less emphasis on the more relevant and (at least) as important types of research that are nevertheless not publishable in leading journals due to excessive formalism. Given this, the policy of excessive or even exclusive emphasis on refereed journal publications adopted by many universities may need to be reconsidered. Some credit to more practical and policy-oriented research should perhaps also be given.

\section{Looking Forward}

Economists' basic tools of constrained maximization and equilibrium are very powerful and will continue to be used. Extensions beyond the simplified class-room models will continue to be made. Even now, there are already many rich results waiting to be incorporated into our textbooks to enrich economic analysis. The imperfect applicability of the simple models means that economists will benefit from knowledge in other areas, 
especially psychology, biology, and institutional studies. On the other hand, associated with excessive formalism is the tendency towards increasing specialization, with specialists knowing very little beyond their own narrow areas of specialization. This raises a question regarding the training of economists. Economists should learn more than just a few highly simplified models. The basic analysis is important and should continue to be taught, but in a less dogmatic way, emphasizing its simplified nature with many complications neglected.

On the basic analysis, there is something that is quite sad but should be reported. We teach the basic microeconomics and macroeconomics in the first year (some also at the preuniversity level, especially in Singapore and Hong Kong), then do them again at a little more advanced level and with a few more topics in the second, with many applications of the basis analysis to various areas of economics over the second and third year. Micro and macro are repeated again at the honours and/or the graduate level though typically using more mathematical analysis and with more advanced stuff taught. With so many repetitions, one should think that the basic stuff should be ingrained in the mind of our graduate students (which is partly why economists are so narrowly minded, being too much influenced by the highly simplified basic models). However, in my decades of experience, wherever I go, most graduate students and intending graduate students cannot satisfactorily answer simple questions on basic economics such as: why must the marginal cost curve cut a continuous U-shaped average cost curve at the minimum point of the latter. In particular, they cannot explain the relevant point intuitively, even for those who manage to provide a valid mathematical proof. I think this shows that our teaching focuses on techniques to the inadequate emphasis on conceptual understanding. Either for teaching, research, or policy advice, I would prefer an economist who really understands the basics to one who knows how to reproduce the bordered Hessian of constrained maximization without understanding the basic concepts of first-year economics. It is more important to make sure that our students truly understand the basic concepts than to teach them advanced mathematical techniques.

Perhaps the fundamental concepts of even basic economics are too abstract for most students. I think it was Arrow who said something like, "You can teach all the important stuffs of economics within a few weeks, but it takes at least a few years for the students to understand them." Perhaps this is why we have to do micro and macro again and again. Now we argue that the basic stuffs are far from adequate and have to include many extensions. With more time spent on the extensions, wouldn't a higher proportion of our students fail to understand the basics? The answer is that students need more time learning the important and expanded subject of economics. The recent proposal to extend the duration of an economics degree from 3 to 4 years makes sense. Economics is an important, abstract, complicated, expanding subject. We need to spend more time and resources if we are to teach it properly, both to those majoring in economics and to students doing business or management.

\section{References}

Arrow, Kenneth J. (1951). An extension of the basic theorems of classical welfare economics. In Proceedings of the Second Berkeley Symposium on Mathematical Statistics and Probability, ed. Neyman, J., Berkeley: University of California Press. 
Buchanan, James M. and Yoon, Yong J. (1999). “Generalized increasing returns, Euler's theorem, and competitive equilibrium. History of Political Economy, 31(3), pp. 511-523.

Chipman, J. S. (1965). The nature and meaning of equilibrium in economic theory. In D. Martindale, ed., Functionalism in Social Sciences; reprinted in Townsend (1971/1980).

Dixon, Huw and Rankin, Neil (1994). Imperfect Competition and Macroeconomics: A Survey. Oxford University Press, 46, pp. 171-199.

Easterly, William (2001). The Elusive Quest for Growth: Economists' Adventures and Misadventures in the Tropics, MIT Press.

Ellison, Glenn (2002). Evolving standards for academic publishing: A q-r theory. Journal of Political Economy, 110(5), 994-1034.

Frank, Robert H. (1997). Conspicuous consumption: Money well spent? Economic Journal, 107, pp. 1832-1847.

Frey, Bruno S. and Stutzer, Alois (2002). What can economists learn from happiness research? Journal of Economic Literature, XL, pp. 402-435.

Guth, Werner, Rolf Schmittberger and Bernd Schwarze. 1982. An Experimental Analysis of U1timatum Bargaining. Journal of Economic Behavior and Organization, 3, pp. 367-388.

Hillman, Arye L. (2002). The World Bank and the persistence of poverty in poor countries. European Journal of Political Economy, 18, pp. 783-795.

Kahneman, Daniel, Knetsch, D. and Thaler, R. (1991). The endowment effect, loss aversion, and status quo bias. Journal of Economic Perspectives, 5, 193-206.

Kaplow, Louis (1996). The optimal supply of public goods and the distortionary cost of taxation. National Tax Journal, 49(4), 513-533.

$\mathrm{Ng}$, Siang and Ng, Yew-Kwang (2001). Welfare-reducing growth despite individual and government optimization. Social Choice and Welfare, 18, 497-506.

$\mathrm{Ng}$, Yew-Kwang (1965). Why do People buy Lottery Tickets? Choices involving Risk and the Indivisibility of Expenditure. Journal of Political Economy, pp. 530-535.

Ng, Yew-Kwang (1977). Aggregate Demand, Business Expectation, and Economic Recovery without Aggravating Inflation. Australian Economic Papers, 130-140.

$\mathrm{Ng}$, Yew-Kwang (1980). Macroeconomics with Non-perfect Competition. Economic Journal, 598-610.

$\mathrm{Ng}$, Yew-Kwang (1982). A micro-macroeconomic analysis based on a representative firm. Economica., 49, 121-140.

Ng, Yew-Kwang (1986). Mesoeconomics. London: Wheatsheaf.

$\mathrm{Ng}$, Yew-Kwang (1992). Business confidence and depression prevention: A mesoeconomic perspective. American Economic Review, 82, 365-371.

$\mathrm{Ng}$, Yew-Kwang (1996). Happiness surveys: Some comparability issues and an exploratory survey based on just perceivable increments. Social Indicators Research, 38(1), 1-29.

$\mathrm{Ng}$, Yew-Kwang (1997). A case for happiness, cardinal utility, and interpersonal comparability. Economic Journal, 107(445), 1848-1858.

$\mathrm{Ng}$, Yew-Kwang (1998). Non-neutrality of money under non-perfect competition: why do economists fail to see the possibility? In Arrow, Ng, and Yang, eds., Increasing Returns and Economic Analysis. London: Macmillan, 1998, pp. 232-252.

$\mathrm{Ng}$, Yew-Kwang (1999a). Utility, informed preference, or happiness? Social Choice and Welfare, 16(2), 197-216.

$\mathrm{Ng}$, Yew-Kwang (1999b). On estimating the effects of events like the Asian financial crisis: A mesoeconomic approach. Taiwan Economic Review, 27(4), 393-412.

Ng, Yew-Kwang (2000a). Efficiency, Equality, and Public Policy: With a Case for Higher Public Spending. Basingstoke, Hampshire: Macmillan.

$\mathrm{Ng}$, Yew-Kwang (2000b). The optimal size of public spending and the distortionary costs of taxation. National Tax J, 52(2), 253-272. 
Ng, Yew-Kwang (2003a). From preference to happiness: Towards a more complete welfare economics. Social Choice and Welfare, forthcoming.

$\mathrm{Ng}$, Yew-Kwang (2003b). Economic Policies in the Light of Happiness Studies. With Reference to Singapore. Singapore Economic Review, 47(2), 199-212.

Ng, Yew-Kwang (2003c). Welfare Economics: Towards A Complete Analysis, Macmillan/Palgrave, U.K.

Oswald, Andrew J. (1997). Happiness and economic performance, Economic Journal, 107, 1815-1831.

Roth, Alvin E. (1995). Bargaining Experiments. In John H. Kagel and Alvin E. Roth (eds.), The Handbook of Experimental Economics. Princeton: Princeton University Press, pp. 253-348.

Rae, John (1834). New Principles of Political Economy. Reprinted as The Sociological Theory of Capital, ed. Mixter, Charles W. (1990), New York: Macmillan.

Townsend, H. ed. (1971/1980). Price Theory, Penguin.

Veblen, Theodor (1899). The Theory of the Leisure Class. New York: Macmillan.

Yang, Xiaokai and Ng, Yew-Kwang (1993), Specialization and Economic Organization. Amsterdam: North-Holland. 